\title{
A Small Percentage of Family Physicians Report Time Devoted to Research
}

\author{
Jennifer R. Voorhees, MD, Imam M. Xierali, PhD, Andrew W. Bazemore, MD, MPH, \\ Robert L. Phillips, Jr., MD, MSPH, Carlos R. Jaén, MD, PhD, and James C. Puffer, MD
}

Despite calls by family medicine organizations to build research capacity within the discipline, few family physicians report research activity. Policy that supports efforts in family medicine research and increases awareness of opportunities for primary care research in the practice setting is essential for family medicine to expand its scholarly foundations. (J Am Board Fam Med 2013;26:7-8.)

For decades, family medicine professional organizations have called for increasing the discipline's capacity for research and scholarly work. ${ }^{1,2}$ There is widespread recognition of the need for relevant research in the primary care setting to improve patient and population outcomes, and family physicians are uniquely poised to conduct such research because they provide the largest volume of health care of any single specialty (nearly 250

This article was externally peer reviewed.

From Thomas Jefferson University, Philadelphia, PA (JRV); Association of American Medical Colleges (AAMC), Washington, DC (IMX); the Robert Graham Center for Policy Studies in Family Medicine and Primary Care, Washington, DC (AWB, RLP); and the American Board of Family Medicine, Lexington, KY (CRJ, JCP).

Funding: Support was provided by the American Board of Family Medicine, which contracts annually for health policy/health services research conducted by the Robert Graham Center for studies related to maintenance of certification and quality.

Conflict of interest: none declared.

Corresponding author: Andrew W. Bazemore, MD, $\mathrm{MPH}$, The Robert Graham Center for Policy Studies in Family Medicine and Primary Care, 1350 Connecticut Avenue, NW Suite 201, Washington, DC 20036 (E-mail: ABazemore@aafp.org). million patient visits annually). ${ }^{3}$ Despite this acute awareness and need, research remains a particular challenge to the profession, and family physicians are minimally involved with the $\mathrm{Na}$ tional Institutes Health compared with other specialties. $^{4,5}$

Of American Board of Family Medicine Maintenance of Certification Examination candidates from 2007 to 2009 ( $\mathrm{n}=28,505), 4.9 \%$ reported spending any time on research, with $3.9 \%$ spending $\leq 10 \%$ of their time, $0.7 \%$ spending $>10 \%$ but $<50 \%$, and $0.3 \%$ spending $>50 \%$ of their time on research (Figure 1). Urban family physicians were more likely to do research compared with rural physicians (5.4\% vs $2.8 \%$, respectively). Men were more likely to report any research activity $(5.3 \%$ vs $4.3 \%)$, but women who performed research were

The paper was submitted for publication while Dr. Xierali was at the American Academy of Family Physicians. He is currently Manager for Public Health and Diversity Data Initiatives at the Association of American Medical Colleges.

Figure 1. Percentage of family physicians reporting time devoted to research in 2007-2009.

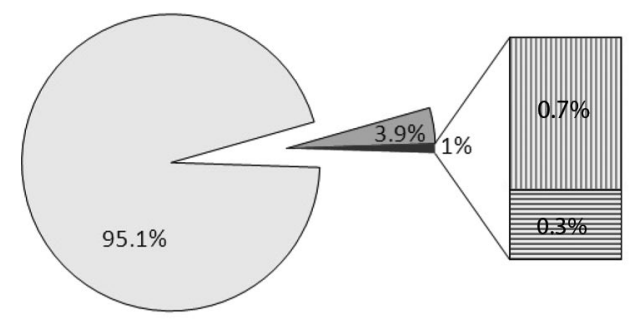

$\square 0 \%$ of Time Devoted to Research

$\square>0 \%$ but $\leq 10 \%$ of Time

प $>10 \%$ but $\leq 50 \%$ of Time

目 $>50 \%$ of Time 
more likely than men to report devoting $>10 \%$ of their time (27\% vs $18 \%)$. Thirty-one percent of full-time faculty and $8 \%$ of part-time faculty members participated in research, compared with $2.5 \%$ of nonfaculty members. Participation was relatively equal across ages.

The effort to promote translation of research into primary care requires more family physicians to be trained as researchers and translators. Family medicine organizations should renew support to build research capacity and push family physicians to incorporate scholarly activity into their practice behavior through targeted continuing medical education/maintenance of certification activities and through assistance with federally mandated quality improvement initiatives. Research advocates and governmental organizations, particularly the National Institutes of Health, should increase the funds available to support a primary care research agenda to enable broader participation of family physicians dedicating sufficient time to important research endeavors.

\section{References}

1. Dickinson WP, Stange KC, Ebell MH, Ewigman BG, Green LA. Involving all family physicians and family medicine faculty members in the use and generation of new knowledge. Fam Med 2000;32:480-90.

2. What does it mean to build research capacity? Fam Med 2002;34:678-84.

3. Hsiao CJ, Cherry DK, Beatty PC, Rechtsteiner EA. National Ambulatory Medical Care Survey: 2007 summary. Natl Health Stat Report 2010;(27):1-32.

4. Lucan SC, Phillips RL Jr, Bazemore AW. Off the roadmap? Family medicine's grant funding and committee representation at NIH. Ann Fam Med 2008;6: 534-42.

5. Ley TJ, Rosenberg LE. The physician-scientist career pipeline in 2005: build it, and they will come. JAMA 2005;294:1343-51. 